\title{
Chronic respiratory diseases and risk factors in 12 regions of the Russian Federation
}

This article was published in the following Dove Press journal:

International Journal of COPD

12 September 2014

Number of times this article has been viewed

\author{
Alexander G Chuchalin' \\ Nikolai Khaltaev ${ }^{2}$ \\ Nikolay S Antonov' \\ Dmitry V Galkin ${ }^{3}$ \\ Leonid G Manakov 4 \\ Paola Antonini ${ }^{5}$ \\ Michael Murphy \\ Alexander G Solodovnikov ${ }^{6}$ \\ Jean Bousquet ${ }^{7}$ \\ Marcelo HS Pereira ${ }^{8}$ \\ Irina $\bigvee$ Demko? \\ 'Institute of Pulmonology, Federal \\ Medical and Biological Agency, \\ Moscow, Russia; ${ }^{2}$ Global Alliance \\ Against Chronic Respiratory Diseases \\ (GARD), Genève, Switzerland; \\ ${ }^{3}$ GlaxoSmithKline, Moscow, Russia; \\ ${ }^{4}$ Far Eastern Scientific Center \\ of Physiology and Pathology of \\ Respiration RAS (Russian Academy \\ of Sciences), Blagoveshchensk, Russia; \\ ${ }^{5}$ Worldwide Clinical Trials, King \\ of Prussia, PA, USA; ' Worldwide \\ Clinical Trials, Ekaterinburg, Russia; \\ ${ }^{7}$ Institut National de la Santé et de \\ la Recherche Médicale, Montpellier, \\ France; ${ }^{8}$ Research and Development \\ Chief Medical Office, International \\ Medical, GlaxoSmithKline, London, \\ United Kingdom; ${ }^{9}$ Krasnoyarsk State \\ Medical University, Krasnoyarsk, \\ Russia
}

Correspondence: Alexander G Chuchalin Institute of Pulmonology, Federal

Medical and Biological Agency,

I I th Parkovaya, 32, 105077 ,

Moscow, Russia

Tel +7 4954655264

$\mathrm{Fax}+74954655264$

Email chuchalin@inbox.ru
Background: Estimation suggests that at least 4 million people die, annually, as a result of chronic respiratory disease (CRD). The Global Alliance against Chronic Respiratory Diseases (GARD) was formed following a mandate from the World Health Assembly to address this serious and growing health problem.

Objectives: To investigate the prevalence of CRD in Russian symptomatic patients and to evaluate the frequency of major risk factors for CRD in Russia.

Methods: A cross-sectional, population-based epidemiological study using the GARD questionnaire on adults from 12 regions of the Russian Federation. Common respiratory symptoms and risk factors were recorded. Spirometry was performed in respondents with suspected CRD. Allergic rhinitis (AR) and chronic bronchitis (CB) were defined by the presence of related symptoms according to the Allergic Rhinitis and its Impact on Asthma and the Global Initiative for Obstructive Lung Disease guidelines; asthma was defined based on disease symptoms; chronic obstructive pulmonary disease (COPD) was defined as a post-bronchodilator forced expiratory volume per 1 second/forced vital capacity ratio $<0.7$ in symptomatic patients, following the Global Initiative for Obstructive Lung Disease guidelines.

Results: The number of questionnaires completed was 7,164 (mean age 43.4 years; $57.2 \%$ female). The prevalence of asthma symptoms was $25.7 \%$, AR $18.2 \%$, and CB $8.6 \%$. Based on patient self-reported diagnosis, $6.9 \%$ had asthma, $6.5 \% \mathrm{AR}$, and $22.2 \% \mathrm{CB}$. The prevalence of COPD based on spirometry in patients with respiratory symptoms was estimated as $21.8 \%$.

Conclusion: The prevalence of respiratory diseases and risk factors was high in Russia when compared to available data. For bronchial asthma and AR, the prevalence for related symptoms was higher than self-reported previous diagnosis.

Keywords: chronic respiratory diseases, GARD, Russia, prevalence

\section{Introduction}

Chronic respiratory diseases (CRDs) are recognized as being the major cause for premature death in adult populations worldwide. Preventable and treatable CRDs include chronic obstructive pulmonary disease (COPD), asthma, and respiratory allergies. ${ }^{1}$

In general, the prevalence of CRD is increasing everywhere and in particular amongst children and the elderly. ${ }^{1}$ The burden of CRD has major adverse effects on the quality of life and disability of affected individuals. It has been predicted that the global burden of CRD will increase considerably in the future, even though many preventable CRDs can be controlled with adequate management in both developed ${ }^{2}$ and developing countries, ${ }^{3,4}$ as well as among deprived populations. ${ }^{5,6}$ However, CRDs remain under-diagnosed and under-treated. ${ }^{7}$ 
To address this global health problem, the Global Alliance against Chronic Respiratory Diseases (GARD) was formed following a mandate from the World Health Assembly. ${ }^{8-12}$ GARD is a voluntary alliance of organizations, institutions, and agencies working towards a common vision to improve global lung health according to local needs. GARD aims to develop a standard way of obtaining relevant data on CRD and risk factors, encourage countries to implement CRD prevention policies and to make recommendations of simple and affordable strategies for CRD management. ${ }^{7}$

The rationale of this study was to investigate the prevalence of COPD in patients with respiratory symptoms, as well as the prevalence of bronchial asthma (BA), allergic rhinitis (AR), and chronic bronchitis (CB) in the overall Russian population. The frequency of major risk factors for CRD was also evaluated in the same study population.

\section{Methods}

This was a cross-sectional population-based epidemiological study conducted in 2010-2011 across 12 regions (Figure S1) of the Russian Federation.

The aim of the study was to recruit 250 adult ( $\geq 18$ years) respondents in each major Russian city. As a general procedure, the administrative districts of each region participating in the study were selected based on a stratified random cluster sampling procedure. This stratification ensured appropriate weighted representation of each district's target population in the study sample. The most current census data from the entire region and from each district were collected from official sources in order to proportionally stipulate the number of participants in each district. In a second stage, streets from each previous selected district were also selected by applying a two-step stratified random cluster sampling procedure with a standard random number generator (Microsoft Excel 2010; Microsoft Corporation, Redmond, WA, USA). ${ }^{13}$ In the last stage, each selected street had also been randomly assigned specific households that would be approached to take part in the study. When blocks of apartments were selected, only several apartments were chosen from the block, and then the interviewers' team moved to the next block randomly. To ensure inclusion of respondents who could not be available, rounds were conducted during non-working time.

GARD study received favorable opinion from the National Ethics Committee, Russian Ministry of Health. Prior to initiating a face-to-face interview by a team that consisted of either a nurse or a physician, subjects gave written consent for the use of the anonymized data reported in the questionnaire (Figure S1) and for pulmonary function testing - applicable to respondents with suspected CRD based on self-reported symptoms. Upon availability of hospital records, patient-reported diagnoses were checked.

The presence of BA symptoms was considered if patients experienced an attack of wheezing, or wheezing/whistling that resulted in breathlessness. AR symptoms were adapted from the Allergic Rhinitis and its Impact on Asthma criteria, according to which the presence of running nose with sneezing or nasal obstruction indicates rhinitis and the presence of running nose alone might also indicate rhinitis. ${ }^{14} \mathrm{CB}$ was defined as the presence of cough and sputum production for at least 3 months in 2 years. ${ }^{15}$

COPD was defined following the Global Initiative for Obstructive Lung Disease definition of post-bronchodilator $\mathrm{FEV}_{1} / \mathrm{FVC}<0.7$. The identification of symptomatic patients included clinical diagnosis of dyspnea, chronic cough or sputum production, ${ }^{15}$ as well as those who were active smokers for more than 1 year, or those exposed to biomass or occupational hazards.

These selection criteria were checked by a doctor/pulmonologist using the GARD questionnaire which was developed in the respondent's native language. As the questionnaire was self-completed by respondents and did not cover all of the information necessary to check the above criteria, the doctor/pulmonologist briefly interviewed the respondents regarding their medical history to establish the pulmonary origin of dyspnea and collect details on allergies and current health condition. In addition, all subjects who had an acute respiratory viral infection at the time of the interview were excluded to ensure reliable pulmonary function tests. Spirometry was performed at the investigational center and in accordance with international standards, including bronchodilator challenge. ${ }^{16}$ For post-bronchodilator measurements, investigators were recommended to perform spirometry 15 minutes after two-four puffs of salbutamol (200-400 $\mu \mathrm{g})$ via metered-dose inhaler with spacer.

\section{Statistical analysis}

The primary study endpoint was to establish prevalence of COPD, BA, and AR in accordance with the current diagnostics standards in the representative population. Using a twotailed binomial test with a significance level of 5\%, the study was designed to have $80 \%$ power to establish prevalence for each disease under study with the significance level not less than $1 \%$ on each side. The calculation of the sample size was made using Stata 12 package (sampsi) (StataCorp LP, College Station, TX, USA). The target sample size of 7,164 respondents was determined using the following assumptions:

- Binomial distribution of the prevalence

- The maximum prevalence for each study indication according to literature was $20 \%$ 
- Maximum acceptable one-sided error for prevalence determination was $5 \%$, which was a $1 \%$ one-sided error for a maximum prevalence of $20 \%$

- Two-sided type 1 error of 5\%, which was the risk to incorrectly accept the false null hypothesis of nonequivalence of sample prevalence and estimated population prevalence

- An $80 \%$ probability to detect non-equivalence of the sample prevalence and the estimated population prevalence in case of true non-equivalence

- A $10 \%$ probability that patients did not show up for the functional testing at the investigational site after the completion of the questionnaire.

The comparison of the qualitative parameters in different groups (by age, sex, etc) was carried out using chi-square test, in the case of two groups, where possible, Fisher's exact test was used. Taking into consideration the cross-sectional nature of the study, odds ratio was calculated and $95 \%$ confidence intervals (CI) for the odds ratio to estimate the statistical significance of associations between risk factors and diseases. As spirometry was performed only in a sub-set population with symptoms and/or risk factors, this association was not calculated. All results were considered statistically significant at the level of $P<0.05$.

\section{Results}

A total of 7,164 questionnaires were completed. The mean age of respondents was 43.4 years, ranging from 18 to
88 years, and $57.2 \%$ were female. Of the respondents, $64.2 \%$ were employed at the time of the survey, and 3.4\% were migrants from other countries.

Respondents' characteristics are shown in Table 1.

\section{Prevalence of BA, AR, and $C B$ related symptoms}

Prevalence of disease related symptoms is shown in Table 2. When respondents were asked if they had ever experienced attacks of wheezing or whistling accompanied with the feeling of breathlessness, 25.7\% (95\% CI: 24.7-26.7) responded affirmatively. Out of those, $78.7 \%$ confirmed they had two or more attacks.

The presence of a running nose along with the presence of at least one of the symptoms of sneezing or nasal congestion was reported among $18.2 \%$ (95\% CI: $17.3-19.2)$ of the study population. Of these, $52.9 \%$ also had ocular symptoms. The distribution of respondents with respiratory symptoms, by age group, is shown in Figure 1.

Cough and expectoration, occurring in the majority of the week for more than three consecutive months in a year, lasting more than 2 years, compatible with $\mathrm{CB}$, was experienced by $8.6 \%$ of all respondents (95\% CI: 7.9-9.3). Frequencies of respiratory symptoms are shown in Table 2.

\section{Prevalence of previous diagnosis}

Out of all respondents participating in the survey, $6.9 \%$ (95\% CI: 6.3-7.5) reported a previous diagnosis of BA at

Table I Demographic characteristics of sample respondents

\begin{tabular}{|c|c|c|c|}
\hline \multirow[t]{3}{*}{ Subjects (n) } & Male & Female & Total \\
\hline & $3,067(42.8 \%)$ & $4,093(57.2 \%)$ & $7,164^{a}$ \\
\hline & (95\% Cl: 4I.7-44.0) & (95\% Cl: 56.0-58.3) & $(n, \%)$ \\
\hline \multicolumn{4}{|l|}{ Age (years) ${ }^{b}$} \\
\hline Below 20 years & $105(3.4 \%)$ & 118 (2.9\%) & $223(3.0 \%)$ \\
\hline $20-29$ years & $769(25.1 \%)$ & $842(20.6 \%)$ & $\mathrm{I}, 6 \mathrm{II}(22.5 \%)$ \\
\hline 30-39 years & $576(18.8 \%)$ & $713(17.4 \%)$ & $1,289(18.0 \%)$ \\
\hline $40-49$ years & $536(17.5 \%)$ & $764(18.7 \%)$ & $\mathrm{I}, 300(18.2 \%)$ \\
\hline $50-59$ years & $591(19.3 \%)$ & $928(22.7 \%)$ & 1,519 (2I.2\%) \\
\hline $60-69$ years & $325(10.6 \%)$ & $484(11.8 \%)$ & $809(11.3 \%)$ \\
\hline $70-79$ years & $139(4.5 \%)$ & $212(5.2 \%)$ & $351(4.9 \%)$ \\
\hline 80 years and older & $25(0.8 \%)$ & $31(0.8 \%)$ & $56(0.8 \%)$ \\
\hline \multicolumn{4}{|l|}{ Smoking status } \\
\hline Have ever smoked & 2,I 32 (69.5\%) (95\% Cl: 67.9-7I.I) & I,I52 (28.1\%) (95\% Cl: 26.8-29.6) & 3,284 (45.9\%) (95\% Cl: 44.7-47.0) \\
\hline Current smokers & I,608 (52.4\%) (95\% Cl: 50.6-54.2) & 792 (19.4\%) (95\% Cl: I8.I-20.6) & 2,400 (33.5\%) (95\% Cl: 32.4-34.6) \\
\hline Exposure to workplace dust & 956 (3I.2\%) (95\% Cl: 29.5-32.8) & 630 (I5.4\%) (95\% Cl: I4.3-I6.5) & I,586 (22.2\%) (95\% Cl: 2I.2-23.I) \\
\hline Exposure to biomass & 960 (3I.3\%) (95\% Cl: $29.7-33.0)$ & I,473 (36.0\%) (95\% Cl: 34.5-37.5) & 2,433 (34.0\%) (95\% Cl: 32.9-35.I) \\
\hline Migration from another country & I2I (3.9\%) (95\% Cl: 3.3-4.7) & 125 (3.1\%) (95\% Cl: $2.5-3.6)$ & 246 (3.4\%) (95\% Cl: 3.0-3.9) \\
\hline \multicolumn{4}{|l|}{ Employment status } \\
\hline Employed & 2,039 (66.5\%) (95\% Cl: 64.8-68.2) & 2,562 (62.6\%) (95\% Cl: 6I.I-64.I) & $4,60 \mathrm{I}(64.3 \%)(95 \% \mathrm{Cl}: 63 . \mathrm{I}-65.3)$ \\
\hline Unemployed & I,027 (33.5\%) (95\% Cl: 3I.8-35.2) & I,530 (37.4\%) (95\% Cl: 35.9-38.9) & 2,557 (35.7\%) (95\% Cl: 34.6-36.8) \\
\hline
\end{tabular}

Notes: a Four respondents did not indicate their sex; 'bix respondents did not indicate their age.

Abbreviation: $\mathrm{Cl}$, confidence interval. 
Table 2 Prevalence of respiratory symptoms in the total sample

\begin{tabular}{|c|c|}
\hline & $\begin{array}{l}\text { Frequency of positive } \\
\text { answer }(n=7,164)\end{array}$ \\
\hline \multicolumn{2}{|l|}{ Asthma } \\
\hline $\begin{array}{l}\text { Attack of wheezing or whistling } \\
\text { with breathlessness }\end{array}$ & $25.7 \%$ (95\% Cl: 24.7-26.7) \\
\hline \multicolumn{2}{|l|}{ Allergic rhinitis } \\
\hline Running nose alone & 19.2\% (95\% Cl: I8.3-20.I) \\
\hline $\begin{array}{l}\text { Running nose with sneezing or } \\
\text { nasal obstruction }\end{array}$ & I8.2\% (95\% Cl: 17.3-19.2) \\
\hline $\begin{array}{l}\text { Ocular symptoms in respondents } \\
\text { with running nose with sneezing or } \\
\text { nasal obstruction }\end{array}$ & $52.9 \%$ (95\% Cl: 50.4-55.3) \\
\hline \multicolumn{2}{|l|}{ Chronic bronchitis } \\
\hline $\begin{array}{l}\text { Cough and sputum production } \\
\text { most of the days of the week } \geq 3 \\
\text { consecutive months } \geq 2 \text { years }\end{array}$ & 8.6\% (95\% Cl: 7.9-9.3) \\
\hline
\end{tabular}

Abbreviation: $\mathrm{Cl}$, confidence interval.

some point in their life. Previous AR diagnosis was also reported by $6.5 \%$ of respondents ( $95 \%$ CI: $5.9-7.1)$. The highest percentage was found among those respondents who had a previous diagnosis of CB (22.2\%; 95\% CI: $21.2 \%-23.2 \%)$.

Of patients with proven COPD based on spirometry results, 51.4\% (95\% CI: 45.0-57.7) and 6.8\% (95\% CI: 4.0-10.6) had also self-reported previous CB and emphysema diagnosis, respectively. When analyzing the pool of respondents with symptoms compatible with $\mathrm{CB}$, only $23.5 \%$
(95\% CI: 21.5-25.7) reported to have a previous diagnosis. Out of those, $25.9 \%$ (95\% CI: 20.6-31.8) had positive COPD diagnosis after spirometry. Distribution of respondents with COPD within spirometry population, by age group, is shown in Figure 2.

\section{Prevalence of COPD based on spirometry}

Spirometry data was recorded in 16\% (251) of the total study sample in patients with suspected CRD. This information was based on both historical and newly performed spirometry data collected as part of the study.

A post-bronchodilator test was performed in $94.4 \%$ of these subjects. Subjects with a post-bronchodilator test had a significantly reduced vital capacity and $\mathrm{FEV}_{1}$ when compared to the total population who had spirometry, and also had a significantly higher age $(P<0.001)$.

The prevalence of COPD in patients with respiratory symptoms, or risk factors, was $21.8 \%$ (95\% CI: $19.5 \%-$ $24.5 \%$ ). By extrapolation, the prevalence of symptomatic COPD in the total study population was $15.3 \%$.

\section{Risk factors}

The prevalence of smoking was quite high, with $45.7 \%$ of the total population responding that they had a smoking history,
A

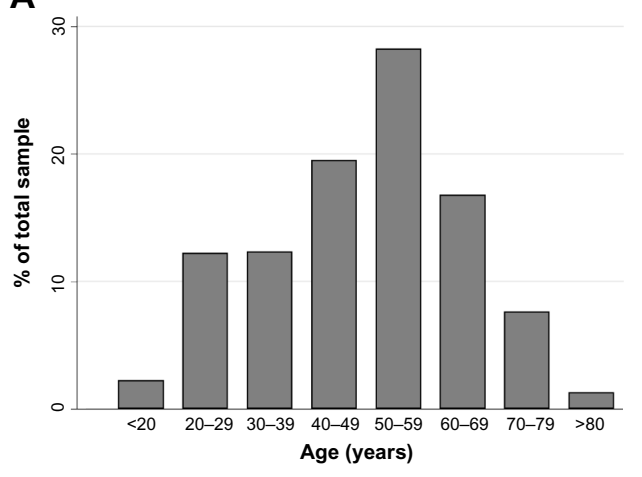

B

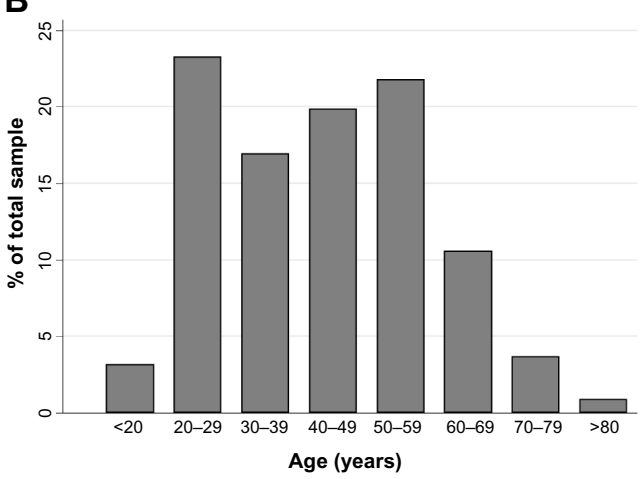

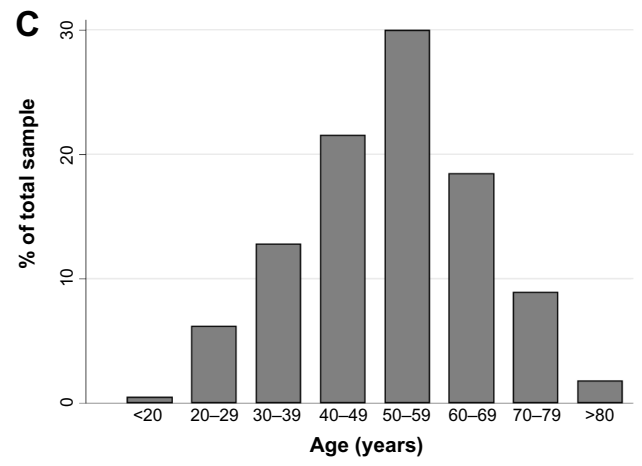

Figure I The distribution of respondents with respiratory symptoms for bronchial asthma, allergic rhinitis, and chronic bronchitis. Notes: (A) Asthma. (B) Allergic rhinitis. (C) Chronic bronchitis. 


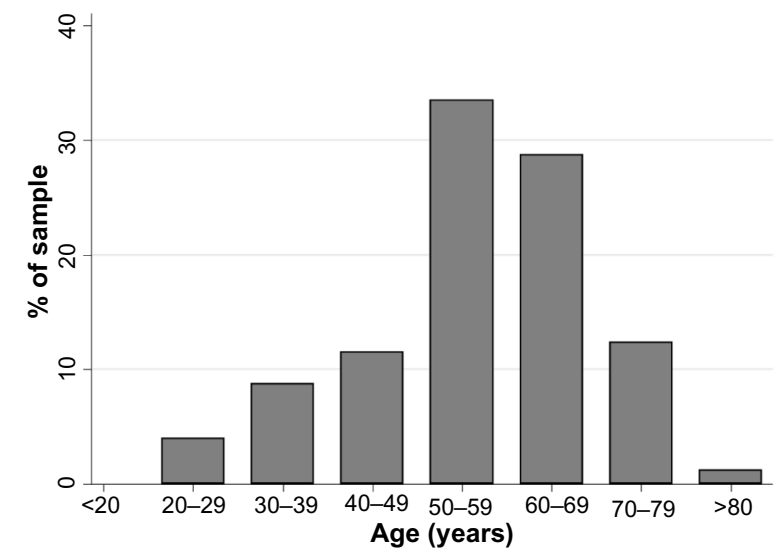

Figure 2 Distribution of respondents with COPD based on GOLD guidelines, by age group.

Abbreviations: COPD, chronic obstructive pulmonary disease; GOLD, Global Initiative for Obstructive Lung Disease.

of which $73.1 \%$ were current smokers. Smoking history was measured if patients have consumed at least 200 packs in their life-time. Regarding workplace dust, $22.2 \%$ of the total population responded that they had been exposed to workplace dust for more than a year. For indoor use of an open fire for heating or cooking, $34.0 \%$ of the total population responded that they used one. The association between these selected risk factors and respiratory symptoms is shown in Table 3.

\section{Discussion}

The GARD study was the first cross-sectional populationbased epidemiological study among a representative sample, using a standardized methodology and validated questionnaire, to evaluate the prevalence of respiratory diseases in several regions of the Russian Federation.

Partial use of data collected from previously completed GARD questionnaires from 2009-2010 was approved by the

Table 3 Association between risk factors and chronic respiratory diseases

\begin{tabular}{|c|c|c|c|}
\hline & \multicolumn{3}{|c|}{ Symptom odds ratio $(95 \% \mathrm{Cl}) ; P$-value } \\
\hline & $\begin{array}{l}\text { Occupational } \\
\text { hazard }\end{array}$ & Smoking & $\begin{array}{l}\text { Biomass } \\
\text { exposure }\end{array}$ \\
\hline $\begin{array}{l}\text { Bronchial } \\
\text { asthma }\end{array}$ & $\begin{array}{l}1.979 \\
(1.737-2.254) \\
<0.0001\end{array}$ & $\begin{array}{l}\text { I.II6 } \\
(0.992-1.255) \\
0.0633\end{array}$ & $\begin{array}{l}1.431 \\
(1.268-1.614) \\
<0.0001\end{array}$ \\
\hline $\begin{array}{l}\text { Chronic } \\
\text { bronchitis }\end{array}$ & $\begin{array}{l}2.584 \\
(2.168-3.080) \\
<0.0001\end{array}$ & $\begin{array}{l}2.617 \\
(2.189-3.129) \\
<0.0001\end{array}$ & $\begin{array}{l}1.677 \\
(1.4 I 5-1.988) \\
<0.0001\end{array}$ \\
\hline $\begin{array}{l}\text { Allergic } \\
\text { rhinitis }\end{array}$ & $\begin{array}{l}\text { I.327 } \\
(1.167-1.509) \\
<0.0001\end{array}$ & $\begin{array}{l}0.760 \\
(0.67 I-0.860) \\
<0.000 I\end{array}$ & $\begin{array}{l}0.979 \\
(0.87|-| . \mid 0) \\
0.7|6|\end{array}$ \\
\hline
\end{tabular}

Abbreviation: $\mathrm{Cl}$, confidence interval. study steering committee. The GARD questionnaire has been used in several studies and has been shown to be an accurate and reliable diagnostic tool. ${ }^{17,18}$

The prevalence of respiratory symptoms in the population sampled was found to be high. The percentage of patients with asthma related symptoms was $25.7 \%$, AR $18.2 \%$ and CB $8.6 \%$.

Based on spirometry-confirmed diagnosis, $21.8 \%$ of respondents with respiratory symptoms had COPD, and, by extrapolations, $15.3 \%$ of the overall population suffered from the disease.

CRDs are recognized as a major public health problem with an increasing morbidity and mortality. With such a high burden on the health care system, emphasis on better diagnosis and management of these diseases must be achieved, and reliable epidemiological data on the prevalence and severity of diseases, such as COPD and its exacerbations, are crucial to guide health care policy. ${ }^{19}$

In the Russian Federation, it has been estimated from earlier epidemiological studies that the prevalence of CRD ranges from $17 \%$ to $21 \%$. This includes the prevalence of asthma which ranges from $6 \%-8 \%$ for adults and up to $12 \%$ for children, and for COPD between $6 \%-7 \%$, and other miscellaneous disease of $2 \%{ }^{20}$

COPD is the fourth cause of death worldwide. ${ }^{21}$ An estimation from the World Health Organization suggests that COPD will be the third cause of death by $2030 .{ }^{22}$ The association between COPD and CB may lead to a more severe COPD prognostic, which encompasses a poorer lung function, exacerbation, a worse quality of life and, consequently, a higher economic burden. ${ }^{23}$ We used the Global Initiative for Obstructive Lung Disease strategy definition of COPD in symptomatic subjects, which represents a simplified case definition for epidemiological purposes, rather than a definitive clinical diagnosis; this may have resulted in patients with COPD not being diagnosed. The limitation of our study is that a large proportion of patients with COPD are asymptomatic; the study may have underestimated the prevalence of COPD as the spirometry was conducted only in symptomatic patients. ${ }^{24}$

The problem of COPD under-diagnosis is well known. Only about one-third of all cases with COPD are recognized by the health care professional, ${ }^{25-27}$ and the proportion of undiagnosed cases decreases with increasing disease severity ${ }^{28}$ The prevalence of COPD has often been reported in the range of $6 \%-10 \%$ of the total adult population. ${ }^{29}$ However, for the PLATINO study, ${ }^{18}$ the crude prevalence of COPD was estimated to be up to $19.7 \%$ in population $\geq 40$ years in 
Montevideo, especially in elderly men. Other studies have also reported prevalence of up to $20 \%$, dependent on the definition used. ${ }^{24,30,31}$ In the BOLD (Burden of Obstructive Lung Disease) Study, prevalence of non-flow obstruction was observed in up to $80 \%$ with variation of COPD prevalence from $0.9 \%$ to $15.5 \%$ among cities, depending on the disease stage. ${ }^{32}$

As the main objective of the GARD study was to assess COPD prevalence in symptomatic patients, the estimation of crude prevalence of $15.3 \%$ should be analyzed carefully, even though our results are compatible with what has been seen in different populations.

The assumption of this prevalence was based on the fact that symptomatic patients who have not undergone spirometry (due to the exclusion criteria being matched or refusals/further contact failure after the first assessment by questionnaire) would also have the same frequency of cases observed in those patients with similar clinical characteristics who underwent spirometry. For the remaining asymptomatic population who did not meet clinical diagnosis criteria, our assumption was that the result of spirometry would be $\geq 0.7$.

COPD itself is a predictor of mortality as it has been shown that this is significantly higher amongst subjects with COPD compared to subjects without COPD $(P<0.001) .{ }^{33}$ This study reinforces the need for the provision of adequate standard care management in order to improve the quality of life of patients and to decrease exacerbations and hospitalizations. ${ }^{34-36}$ Our results suggest that prevalence of COPD in Russia is higher than previously suggested, which also results in a greater health issue.

The prevalence of $\mathrm{CB}$ in COPD patients varies substantially. ${ }^{23,37}$ In the GARD study, more than half of the patients with COPD also had CB. In a recent European study, ${ }^{38} \mathrm{CB}$ prevalence varies from $0.7 \%$ to $9.7 \%$, going up to $20.1 \%-56.9 \%$ among current smoker respondents, as smoking is one of the major risk factors for developing $\mathrm{CB}$, which can also be seem from our study results. Our findings suggested that prevalence based on CB symptoms is $8.6 \%$, which is consistent with the findings in European populations.

The prevalence of BA may vary considerably in different countries, from $4 \%$ to $18 \%$ of populations. ${ }^{39}$ Even though BA is much more present in developed countries, its prevalence in less industrialized regions is growing. ${ }^{40}$ Our findings suggest that in Russia, the prevalence of BA related-symptoms is higher than originally estimated. ${ }^{20}$ Asthma is one of the most common chronic diseases in the world and it is esti- mated to be accountable for about one in every 250 deaths worldwide. ${ }^{41}$ A study performed by Brogger et al suggested a 3-fold increase in the prevalence of self-reported diagnosis in 26 years, which could be due to a better standard of care and an easier access to physicians. ${ }^{42}$

As for other CRDs, AR is also experiencing an increase of epidemic proportion, ${ }^{43}$ which leads to an intensification in the socioeconomic burden of the disease across the world. Prevalence of AR has been reported as high as $21 \%$ in Europe. ${ }^{44}$ Asthma and rhinitis have been reported to have similarities related to their epidemiological and patho-physiological background. ${ }^{45}$ If untreated, rhinitis may have considerable economic and quality of life implications. ${ }^{46,47}$

A high proportion of the Russian population is exposed to risk factors which could drive specific public health initiatives. In this study, the odds ratios between BA, CB, and AR and occupational hazard, smoking, and biomass exposure were estimated as an attempt to collect information on the major risk factors for those CRDs. The present study did not intend to assess risk factor related to COPD, nor the difference pattern between genders and cities. The prevalence of major risk factors including smoking, occupational hazards, and biomass exposure was high.

The major effects of smoking on CRDs have been extensively recorded over more than 40 years. ${ }^{48}$ The associations found in this study were generally consistent with findings from other epidemiological studies where the GARD questionnaire has been used. ${ }^{17,18}$ It should be noted, however, that this study design (cross-sectional) was not performed to evaluate causality between risk factors and respiratory disease already established in other studies. Among all three risk factors, the occurrence of an occupational hazard demonstrated a statistically significant association with all respiratory symptoms $(P<0.0001)$. Biomass exposure occurrence had a positive association with $\mathrm{CB}$ and $\mathrm{BA}$, which was also statistically significant $(P<0.0001)$. The negative association between smoking and AR should be analyzed carefully. Some risk factors may be obscured due to changes in smoke habits due to the occurrence of respiratory symptoms. Also, for those respondents with a history of respiratory symptoms, there is a possibility of reluctance to start smoking. All of these factors may create a bias in the risk factors association analysis due to the cross-sectional design study type.

This study has substantial strengths. To the best of our knowledge, it is the first comprehensive prevalence study conducted in Russia for CRD. Using probabilistic sampling strategy, the study was able to capture the prevalence of 
symptomatic CRD and the major risk factors in the Russian Federation. There are also potential limitations of the study, which included only symptomatic patients and did not represent the total number of COPD patients. Moreover not all self-reported symptomatic patients underwent spirometry due to the reasons previously explained.

Furthermore, as for any questionnaire based study, the study outcomes are based on the willingness of the respondents to report their diseases. Furthermore, by also having the prevalence of self-reported symptoms we are minimizing the subjectivity of self-report diagnosis due to the different diagnosis criteria that may be used by physicians. There is also a potential bias of non/incomplete-responders, as we did not adjust for subjects who did not complete all of the questions during the visit. In addition, no adjustments for age or sex have been made. Our sample includes 57\% females which could have an impact on prevalence as there may be important sex differences on the perception of dyspnea, health status, and physical activity limitation. ${ }^{49}$

\section{Conclusion}

The prevalence of respiratory symptoms in the Russian Federation was found to be high. For asthma, the overall asthmatic symptoms were present in $25.7 \%$ of respondents. AR symptoms were presented in $18.2 \%$ and $\mathrm{CB}$ in $8.6 \%$.

The estimated prevalence of $21.8 \%$ for COPD in symptomatic patients and $15.3 \%$ in the overall population may still be an underestimate as this was only estimated by spirometry from symptomatic patients. COPD can be present in asymptomatic patients which also may reflect a misrepresentation of prevalence present in this study. There was a considerable discrepancy between self-reported diagnosis and disease based-symptoms for $\mathrm{AR}$ and BA, which may suggest that respondents were under-diagnosed. The discrepancy between self-reported symptoms and previous diagnosis highlights the fact that CDR may not be recognized, or may have a late diagnosis which might lead to economic and health impacts. This data will be used to monitor the course and health care utilization of these diseases and to evaluate the impact of future educational programs on assessing and treating patients with CRDs.

\section{Acknowledgments}

The authors wish to acknowledge Diana Jones of Cambrian Clinical Associates Ltd for the development of the first draft of the manuscript, editorial suggestions to draft versions of this paper, assembling tables and figures, collating author comments, and referencing. This assistance was funded by GlaxoSmithKline.
The study was supported from the grant provided by GlaxoSmithKline Russia to the contract-research organization "Worldwide Clinical Trials". Worldwide Clinical Trials has conducted the study and assisted in developing the study protocol to investigators. This study was supported by ZAO GlaxoSmithKline Trading Ltd.

\section{Author contributions}

All listed authors meet the criteria for authorship set forth by the International Committee for Medical Journal Editors. Conception and design: AGC, IVD, DVG, NSA, NK and LGM. Analysis and interpretation: AGS. All authors were responsible for drafting and editing the manuscript. All authors contributed toward data analysis, drafting and revising the paper and agree to be accountable for all aspects of the work.

\section{Disclosure}

The authors report no conflicts of interest in this work.

\section{References}

1. World Health Organization. Global Surveillance, Prevention and Control of Chronic Respiratory Diseases. A Comprehensive Approach. Geneva: World Health Organization; 2007. Available from: http://www. who.int/gard/publications/GARD\%20Book\%202007.pdf. Accessed July 17, 2014.

2. Haahtela T, Tuomisto LE, Pietinalho A, et al. A 10 year asthma programme in Finland: major change for the better. Thorax. 2006;61(8): 663-670.

3. Fairall LR, Zwarenstein M, Bateman ED, et al. Effect of educational outreach to nurses on tuberculosis case detection and primary care of respiratory illness: pragmatic cluster randomised controlled trial. BMJ. 2005;331(7519):750-754

4. Fischer GB, Camargos PA, Mocelin HT. The burden of asthma in children: a Latin American perspective. Paediatr Respir Rev. 2005;6(1):8-13.

5. Evans R III, Gergen PJ, Mitchell H, et al. A randomized clinical trial to reduce asthma morbidity among inner-city children: results of the National Cooperative Inner-City Asthma Study. $J$ Pediatr. 1999;135(3):332-338.

6. Cloutier MM, Hall CB, Wakefield DB, Bailit H. Use of asthma guidelines by primary care providers to reduce hospitalizations and emergency department visits in poor, minority, urban children. J Pediatr. 2005;146(5):591-597.

7. Bousquet J, Dahl R, Khaltaev N. Global alliance against chronic respiratory diseases. Allergy. 2007;62(3):216-223.

8. Khaltaev N. WHO strategy for prevention and control of chronic obstructive pulmonary disease. Exp Lung Res. 2005; 31(Suppl 1):55-56.

9. World Health Organization. WHO Strategy for Prevention and Control of Chronic Respiratory Diseases. Geneva: World Health Organization; 2001. Available from: http://www.who.int/respiratory/publications/ WHO_MNC_CRA_02.1.pdf. Accessed July 17, 2014.

10. World Health Organization. Implementation of the WHO Strategy for Prevention and Control of Chronic Respiratory Diseases. Geneva: World Health Organization; 2002. Available from: http://www.who. int/respiratory/publications/WHO_MNC_CRA_02.2.pdf. Accessed July 17, 2014. 
11. World Health Organization. Prevention and Control of Chronic Respiratory Diseases in Low and Middle-Income African Countries: A Preliminary Report. Geneva: World Health Organization; 2004. Available from: http://whqlibdoc.who.int/hq/2003/WHO_NMH_ CRA_04.1.pdf. Accessed July 17, 2014.

12. World Health Organization. Prevention and Control of Chronic Respiratory Diseases at Country Level: Towards a Global Alliance against Chronic Respiratory Diseases. Geneva: World Health Organization; 2005. Available from: http://www.who.int/respiratory/ publications/WHO_NMH_CHP_CPM_-CRA_05.1.pdf. Accessed July 17, 2014.

13. Silman AJ, Macfarlane GJ. Epidemiological Studies: A Practical Guide. 2nd ed. Cambridge: Cambridge University Press; 2002.

14. Allergic Rhinitis and its Impact on Asthma (ARIA). Management of Allergic Rhinitis and its Impact on Asthma. Pocket Guide. ARIA; 2007. Available from: http://www.whiar.org/docs/ARIA_PG_08_View_ WM.pdf. Accessed July 17, 2014.

15. Global Initiative for Chronic Obstructive Lung Disease. Global Strategy for the Diagnosis, Management and Prevention of Chronic Obstructive Pulmonary Disease. Global Initiative for Chronic Obstructive Lung Disease; 2014. Available from: http://www.goldcopd.org/uploads/ users/files/GOLD_Report2014_Feb07.pdf. Accessed July 17, 2014

16. Miller MR, Hankinson J, Brusasco V, et al. Standardisation of spirometry. Eur Respir J. 2005;26(2);319-338.

17. Mohammad Y, Shaaban R, Yassine F, et al. Executive summary of the multicenter survey on the prevalence and risk factors of chronic respiratory diseases in patients presenting to primary care centers and emergency rooms in Syria. J Thorac Dis. 2012;4(2):203-205.

18. Menezes AM, Perez-Padilla R, Jardim JR, et al; for the PLATINO Team. Chronic obstructive pulmonary disease in five Latin American cities (the PLATINO study): a prevalence study. Lancet. 2005;66(9500): 1875-1881.

19. Martins P, Rosado-Pinto J, do Céu Teixeira M, et al. Under-report and underdiagnosis of chronic respiratory diseases in an African country. Allergy. 2009;64(7):1061-1067.

20. Bellevskiy A. GARD in Russia. Geneva: World Health Organization. Available from: http://www.who.int/gard/news_events/GARD $\% 20$ in\%20Russia.pdf. Accessed July 17, 2014.

21. Pauwels RA, Rabe KF. Burden and clinical features of chronic obstructive pulmonary disease (COPD). Lancet. 2004;364(9434):613-620.

22. http://www.who.int [homepage on the Internet]. World Health Organization. COPD predicted to be third leading cause of death in 2030. Available from: http://www.who.int/respiratory/copd/World_ Health_Statistics_2008/en/. Accessed July 17, 2014.

23. de Oca MM, Halbert RJ, Lopez MV, et al. The chronic bronchitis phenotype in subjects with and without COPD: the PLATINO study. Eur Respir J. 2012;40(1):28-36.

24. Halbert RJ, Isonaka S, George D, Iqbal A. Interpreting COPD prevalence estimates: what is the true burden of disease? Chest. 2003;123(5):1684-1692.

25. Lundbäck B, Lindberg A, Lindström M, et al. Not 15 but $50 \%$ of smokers develop COPD? - Report from the Obstructive Lung Disease in Northern Sweden Studies. Respir Med. 2003;97(2):115-122.

26. Siafakas NM, Vermeire P, Pride NB, et al. Optimal assessment and management of chronic obstructive pulmonary disease (COPD). The European Respiratory Society Task Force. Eur Respir J. 1995;8(8): 1398-1420.

27. Lindberg A, Bjerg A, Rönmark E, Larsson LG, Lundbäck B. Prevalence and underdiagnosis of COPD by disease severity and the attributable fraction of smoking. Report from the Obstructive Lung Disease in Northern Sweden Studies. Respir Med. 2006;100(2):264-272.

28. Lindberg A, Larsson LG, Muellerova H, Rönmark E, Lundbäck B. Up-to-date on mortality in COPD - report from the OLIN COPD study. BMC Pulm Med. 2012;12:1.
29. Viegi G, Pedreschi M, Pistelli F, et al. Prevalence of airways obstruction in a general population: European Respiratory Society vs American Thoracic Society definition. Chest. 2000;117(5 Suppl 2):339S-345S.

30. Celli BR, Halbert RJ, Isonaka S, Schau B. Population impact of different definitions of airway obstruction. Eur Respir J. 2003;22(2):268-273.

31. Bateman ED, Bousquet J, Busse WW, et al. Stability of asthma control with regular treatment: an analysis of the Gaining Optimal Asthma controL (GOAL) study. Allergy. 2008;63(7):932-938.

32. Buist AS1, McBurnie MA, Vollmer WM, et al. International variation in the prevalence of COPD (the BOLD Study): a population-based prevalence study. Lancet. 2007;370(9589):741-750.

33. Paggiaro PL, Dahle R, Bakran I, Frith L, Hollingworth K, Efthimiou J. Multicentre randomised placebo-controlled trial of inhaled fluticasone propionate in patients with chronic obstructive pulmonary disease. International COPD Study Group. Lancet. 1998;351(9105):773-780.

34. Friedman M, Serby CW, Menjoge SS, Wilson JD, Hilleman DE, Witek TJ Jr. Pharmacoeconomic evaluation of a combination of ipratropium plus albuterol compared with ipratropium alone and albuterol alone in COPD. Chest. 1999;115(3):635-641.

35. Calverley P, Pauwels R, Vestbo J, et al. Combined salmeterol and fluticasone in the treatment of chronic obstructive pulmonary disease: a randomised controlled trial. Lancet. 2003;361(9356):449-456.

36. Masoli M, Fabian D, Holt S, Beasley R; Global Initiative for Asthma (GINA) Program. The global burden of asthma: executive summary of the GINA Dissemination Committee Report. Allergy. 2004;59(5):469-478.

37. Corhay JL, Vincken W, Schlesser M, Bossuyt P, Imschoot J. Chronic bronchitis in COPD patients is associated with increased risk of exacerbations: a cross-sectional multicentre study. Int $J$ Clin Pract. 2013;67(12):1294-1301.

38. Cerveri I, Accordini S, Verlato G, et al. Variations in the prevalence across countries of chronic bronchitis and smoking habits in young adults. Eur Respir J. 2001;18(1):85-92.

39. Global Initiative for Asthma. Global Strategy for Asthma Management and Prevention. Global Initiative for Asthma; 2014. Available from: http://www.ginasthma.org/local/uploads/files/GINA_Report_March13. pdf. Accessed July 17, 2014.

40. Braman SS. The global burden of asthma. Chest. 2006; 130(Suppl 1):4S-12S

41. Bateman ED, Boushey HA, Bousquet J, et al. Can guideline-defined asthma control be achieved? The Gaining Optimal Asthma Control Study. Am J Respir Crit Care Med. 2004;170(8):836-844.

42. Brogger J, Bakke P, Eide GE, Johansen B, Andersen A, Gulsvik A. Long-term changes in adult asthma prevalence. Eur Respir $J$. 2003;21(3):468-472.

43. Pawankar R, Bunnag C, Khaltaev N, Bousquet J. Allergic rhinitis and its impact on asthma in Asia Pacific and the ARIA Update 2008. World Allergy Organ J. 2012;5(Suppl 3):S212-S217.

44. Janson C, Anto J, Burney P, et al. The European Community Respiratory Health Survey: what are the main results so far? European Community Respiratory Health Survey II. Eur Respir J. 2001;18(3):598-611.

45. Gaugris S, Sazonov-Kocevar V, Thomas M. Burden of concomitant allergic rhinitis in adults with asthma. J Asthma. 2006;43(1):1-7.

46. Fineman SM. The burden of allergic rhinitis: beyond dollars and cents. Ann Allergy Asthma Immunol. 2002;88(4 Suppl 1):2-7.

47. Schoenwetter WF, Dupclay L Jr, Appajosyula S, Botteman MF, Pashos CL. Economic impact and quality-of life burden of allergic rhinitis. Curr Med Res Opin. 2004;20(3):305-317.

48. Spencer S, Jones PW; GLOBE Study Group. Time course of recovery of health status following an infective exacerbation of chronic bronchitis. Thorax. 2003;58(7):589-593.

49. Lopez Varela MV, Montes de Oca M, Halbert RJ, et al. Sex-related differences in COPD in five Latin American cities: the PLATINO study. Eur Respir J. 2010;36(5):1034-1041. 


\section{Supplementary material}

Figure S1 Burden of major respiratory diseases: chronic respiratory diseases core questionnaire.

These questions pertain mainly to your chest. Please answer yes or no if possible. If you are in doubt about whether your answer is yes or no, please answer no.

\section{COUGH}

1A. Do you usually have a cough? (Count a cough

1. No 2. Yes with first smoke or on first going out-of-doors. Exclude clearing of throat.) [If no, skip to Question 2A.]

1B. Do you usually cough as much as 4 to 6 times a day,

1. No 2. Yes 4 or more days out of the week?

IF YES TO ANY OF ABOVE (1A, 1B), ANSWER 1C and 1D

1C. Do you usually cough like this on most days for

1. No 2. Yes 3 consecutive months or more during the year?

1D. For how many years have you had this cough?

\section{PHLEGM}

2A. Do you usually bring up phlegm from your chest?

1. No 2. Yes (Count phlegm with the first smoke or on first going out-of-doors. Exclude phlegm from the nose. Count swallowed phlegm.) [If no, skip to 3A.]

2B. Do you usually bring up phlegm like this as much as twice a day, 4 or more days out of the week?

1. No 2. Yes

IF YES TO ANY OF THE ABOVE (2A, 2B), ANSWER 2C AND 2D

2C. Do you bring up phlegm like this on most days

1. No 2. Yes for 3 consecutive months or more during the year?

2D. For how many years have you had trouble with phlegm? years

\section{WHEEZING}

3A. Have you ever had an attack of wheezing that

1. No 2. Yes has made you feel short of breath?

IF YES TO 3A, ANSWER 3B, 3C, AND 3D

3B. How old were you when you had your first such attack?

Age in years

3C. Have you had 2 or more such episodes?

1. No 2. Yes

3D. Have you ever required medicine or treatment

1. No 2. Yes for the(se) attack(s)? 


\section{BREATHLESSNESS}

4. If disabled from walking by any condition other than heart or lung disease, please describe and then proceed to 6A. Nature of condition(s):

5A. Are you troubled by shortness of breath when

1. No 2. Yes hurrying on the level or walking up a slight hill?

IF YES TO 5A, ANSWER 5B, 5C, 5D, 5E
5B. Do you have to walk slower than people of your
1. No
2. Yes age on the level because of breathlessness?
5C. Do you ever have to stop for breath when walking
1. No
2. Yes at your own pace on the level?
5D. Do you ever have to stop for breath after walking
1. No
2. Yes about 100 yards (or after a few minutes) on the level?
5E. Are you too breathless to leave the house or
1. No
2. Yes breathless on dressing or undressing?

We are going to ask you some questions on medical problems that you may have now or may have had in the past.

\section{EMPHYSEMA}

6A. Has a doctor ever told you that you had emphysema?

1. No

2. Yes

\section{ASTHMA}

7A. Has a doctor ever told you that you have asthma?

1. No

2. Yes

IF YES TO 7A, ANSWER 7B, 7C, 7D

7B. Do you still have it?

7C. At what age did it start?

7D. If you no longer have it, at what age did it stop?
1. No__ 2. Yes

Age in years Age in years

\section{TB}

8A. Has a doctor ever told you that you had TB?

1. No

2. Yes

IF YES TO 8A, ANSWER 8B, 8C, 8D
8B. Do you still have it?
$8 \mathrm{C}$. At what age did it start?
8D. If you no longer have it, at what age did it stop?

1. No 2. Yes

Age in years Age in years

\section{PNEUMONIA}

9A. Has a doctor ever told you that you had pneumonia?

1. No

2. Yes

IF YES TO 9A, ANSWER 9B, 9C, 9D

9B. Do you still have it?

9C. At what age did it start?

9D. If you no longer have it, at what age did it stop?
1. No_ 2. Yes Age in years Age in years 


\section{ALLERGIC RHINITIS}

10A. Has a doctor ever told you that you had allergic rhinitis?

1. No 2. Yes

IF YES TO 10A, ANSWER 10B, 10C, 10D

10B. Do you still have it?

10C. At what age did it start?

10D. If you no longer have it, at what age did it stop?
1. No

2. Yes Age in years Age in years

\section{OTHER RESPIRATORY DISEASE(S)}

11A. Has a doctor ever told you that you had another respiratory disease?

1. No 2. Yes

Please specify

IF YES TO 11A, ANSWER 11B, 11C, 11D

11B. Do you still have it?

11C. At what age did it start?

11D. If you no longer have it, at what age did it stop?
1. No 2. Yes

Age in years Age in years

12. Are you taking medicine for active tuberculosis?

1. No 2. Yes

13. Have you ever had chest surgery in which a part

1. No 2. Yes of your lung was removed?

\section{HEART TROUBLES AND ATTACKS}

14A. Has a doctor ever told you that you had heart trouble?

1. No 2. Yes

IF YES to $14 \mathrm{~A}$, answer 14B

14B. Have you had treatment for heart trouble

1. No 2. Yes in the past 10 years?

15. Have you ever been told by a doctor that you have had a heart

1. No 2. Yes attack (myocardial infarction, coronary occlusion, coronary thrombosis)?

\section{OCCUPATION}

16. Have you ever worked for a year or more in any dusty job?

1. No 2. Yes

\section{TOBACCO SMOKING}

\section{Cigarettes}

17A. Have you ever smoked cigarettes? (No means less than 20 packs of cigarettes or $12 \mathrm{oz}$ of tobacco in a lifetime or less than 1 cigarette a day for 1 year).

IF YES TO 17A, ANSWER 17B, 17C, 17D, 17E, 17F

17B. Do you now smoke cigarettes (as of 1 month ago)?

17C. How old were you when you first started regular cigarette smoking?
1. No 2. Yes 
17D. If you have stopped smoking cigarettes completely, how old were you when you stopped?

Age stopped, in years

17E. How many cigarettes do you smoke per day now?

or still smoking

17F. On the average of the entire time you smoked, cigarettes/day cigarettes/day how many cigarettes did you smoke per day?

\section{INDOOR HEATING AND COOKING}

18A. Do you cook using an open fire?

1. No

2. Yes

IF YES TO QUESTION 18A, ANSWER 18B, 18C

18B. What kind of stove/fuel do you use mostly for cooking?
18B.1. coal or coke
18B.2. wood
18B.3. animal dung

1. No

2. Yes

1. No

2. Yes

1. No

2. Yes

18B.4. other

1. No

2. Yes

18C. On average how long have you spent cooking with your stove each day over the last four weeks?

MINUTES

\section{MIGRATION}

19. Have you migrated from another country?

1. No

2. Yes

IF YES TO QUESTION 19, specify the country

\section{SOCIAL}

21. Your present job

1. No 2. Yes

Specify the country

\section{Publish your work in this journal}

The International Journal of COPD is an international, peer-reviewed journal of therapeutics and pharmacology focusing on concise rapid reporting of clinical studies and reviews in COPD. Special focus is given to the pathophysiological processes underlying the disease, intervention programs, patient focused education, and self management protocols.
This journal is indexed on PubMed Central, MedLine and CAS. The manuscript management system is completely online and includes a very quick and fair peer-review system, which is all easy to use. Visit http://www.dovepress.com/testimonials.php to read real quotes from published authors. 